\title{
Epidemiological Characteristics of Traumatic Spinal Cord Injuries in Multi-Center Retrospective Study in Northwest China, 2017-2020.
}

\section{Xiaohui Wang}

Honghui Hospital, Xi'an Jiaotong University

Chao Jiang

Honghui Hospital, Xi'an Jiaotong University

Jinpeng Du

Honghui Hospital, Xi'an Jiaotong University

Yongyuan Zhang

Honghui Hospital, Xi'an Jiaotong University

Fang Tian

Honghui Hospital, Xi'an Jiaotong University

\section{Zhe Chen}

Honghui Hospital, Xi'an Jiaotong University

\section{Yuyang Zhang}

Honghui Hospital, Xi'an Jiaotong University

\section{Zhiyuan Wang}

Honghui Hospital, Xi'an Jiaotong University

\section{Ying Zhang}

Yulin No.2 Hospital

\section{Liang Yan}

Honghui Hospital, Xi'an Jiaotong University

Dingjun Hao ( $\boldsymbol{Q}$ haodingjun@mail.xjtu.edu.cn )

Honghui Hospital, Xi'an Jiaotong University

\section{Research Article}

Keywords: Trauma, Epidemiology, Traumatic spinal cord injuries, COVID-19, Northwest China

Posted Date: January 7th, 2022

DOI: https://doi.org/10.21203/rs.3.rs-1147921/v1 
License: (c) (i) This work is licensed under a Creative Commons Attribution 4.0 International License. Read Full License 


\section{Abstract}

Introduction: Traumatic spinal cord injuries (TSCI) are worldwide public health problems. There has been a lack of extensive multi-center study of TSCl epidemiology in Northwest China in pre- and post-pandemic period of COVID-19.

Materials and Methods: A multi-center retrospective study of 14 hospitals of Northwest China was conducted on patients with TSCI between 2017 and 2020. Variables assessed included patient demographics, etiology, segmental distribution, treatment, waiting time for treatment and outcomes.

Results: The number of patients with TSCl showed an increasing trend from 2017 to 2019 while there were fewer patients in 2020 than in 2019. The male-to-female ratio was 3.67:1 and the mean age was 48 \pm 14.9. The major cause of TSCI was high fall (38.8\%), low fall (27.7\%), traffic accidents (23.9\%), sports $(2.6 \%)$ and others $(7.0 \%)$. The segmental distribution showed a bimodal pattern, peak segments were $\mathrm{C} 6$ and TI1, L1 (14.7\%) was the most frequently injured segments. Incomplete injury (72.8\%) occurred more often than complete injury (27.2\%). ASIA scale of most patients did not change before and after treatment both in operational or conservative group. 975 patients from urban and 1646 patients from rural areas were conducted, most urban residents could rush to get treatment after injured immediately $(<1 \mathrm{~h})$, whereas most rural patients get treatment spend several hours since injured. The rough annual incidence from 2017-2020 are 112.4, 143.4,152.2 and 132.6 per million people calculated by the population-coverage-rate.

Conclusion: The incidence of TSCl in Northwest China is high and growing. However, under the pandemic policy reasons, it has decreased in 2020 . The promotion of online work may be an effective primary prevention measures for trauma. Also, due to the distance from the hospitals with proper conditions, rural patients need to spend long time to there, the timely treatment of them should be paid attention.

\section{Introduction}

Traumatic spinal cord injuries (TSCl) can cause significant morbidity and mortality. [1] These injuries often caused by heavy injuries, traffic accidents, falling accidents, etc., and are centred occur in the range of the labor age population and elderly population. $[2,3]$ Despite the economic differences between countries or regions, this traumatic disease has caused a large loss of working population, imposing a serious economic burden to patients and families, and which lead to high health expenditure and economic losses. $[4,5]$ Unfortunately, there is currently no effective treatment for patients with TSCl severe damage to the spinal cord usually means permanent impairment. $[4,6,7]$ Therefore, attention should be paid to primary prevention. The understanding of injury risk factors, incidence and demographic characteristics can better guide the promotion of preventive measures and the allocation of medical resources. $[8,9]$

The overall global incidence of TSCI was 10.5 cases per 100,000 persons, but the incidence of TSCI varies across countries and regions. [1] China is a country with rapid industrial development and frequent 
traffic flow, this brings more injury-causing factors, and the spinal trauma caused by it also increases year by year. [10] Therefore, it is necessary to update Chinese TSCl incidence data in real time. However, most of the existing studies have focused on East China, while there has been a lack of extensive multi-center review of TSCl epidemiology in Northwest China in recent years. [6, 11-14] The level of economic development in Northwest China is far behind that in East and Mid-China region, and their characteristics of injury factors should be different, so its epidemiological data cannot fully refer to the data in East\&Mid region.

In this study, we aimed to discuss the epidemiological characteristics and risk factors of TSCI in Northwest China. We used multi-center retrospective data from 2017-2020 to optimize previous studies by taking into account the impact of COVID-19 on society. [15]

\section{Materials And Methods}

\section{Location and participants}

Northwest China comprises five provinces or autonomous regions: Shaanxi, Gansu, Ningxia, Qinghai and Xinjiang, with a total population of 102.8 million. We chose Shaanxi and Qinghai, two provinces with representative development levels, as shown in figure 1a. Shaanxi Province (SN) is a traditional industrial and agricultural region, with a population of 38.8 million, Qinghai Province $(\mathrm{QH})$ is an animal husbandry region rich in mineral resources, located in the northern part of the Qinghai-Tibet Plateau, with a population of 6.1 million. In order to better distribute the research work, Shaanxi is further divided into northern, central and southern parts (SN-N, SN-C, SN-S) according to climate and physiognomy. We dispatched investigators to the four regions separately and selected 3-4 hospitals with different administrative levels (provincial, municipal, county) in each region, a total of 14 hospitals, as shown in figure $1 \mathrm{~b}$. The patients' information was gathered from the medical records in these 14 hospitals during January 2017 and December 2020.

\section{Study setting}

Eligible patients are screened by International Classification of Diseases, Version 10 (ICD-10) and its diagnostic code of TSCl. The final diagnosis is based on the patient's diagnosis at discharge/death. Four researchers retrospectively reviewed the medical records of 2621 patients with TSCI admitted to the 14 hospitals in these two representative provinces. between 1st January 2017 and 31 st December 2020. The acquired information from patients' medical records included the patients' name, age, gender, occupation, marital status, time of injury, cause of injury, level of injury, severity of injury, acceptance of surgical treatment, operative mode/approach, damaged segments, preoperative and postoperative scores, rehabilitation therapy, hospital duration, medical costs, and so on.

\section{Executive Organization and Ethics Statement}


This project is jointly undertaken by China Center for Disease Control (China CDC) and Honghui Hospital of Xi'an Jiaotong University. This study was approved by the ethics committee of Honghui Hospital of Xi'an Jiaotong University. The institutional review boards of the sampled hospitals approved the review process and waived the requirement to obtain patients' written informed consent. We confirm that all methods were performed in accordance with the Declaration of Helsinki.

\section{Statistical Analysis}

All numerical data conforming to normal distribution were expressed as $s$ the mean \pm standard deviation (SD). The analysis of variance (ANOVA) and $c^{2}$ tests were used to analyze continuous and categorical data, Wilcoxon rank-sum tests were applied to examine the differences between the non-normally distributed continuous variables, and frequency analysis was used for examining data and calculating percentages. The experimental data was used to analyzed by SPSS 22.0 (SPSS Inc, Chicago). The figures were made by GraphPad Prism7 (GraphPad Software, CA). P $<0.05$ were considered as significant difference.

\section{Results}

\section{General demographic characteristics of patients with TSCI from 2017-2020}

A total of 2621 patients form 14 hospitals with TSCl were identified in this study (figure. 1b and figure. 2). As shown in Table 1, out of these patients with $\mathrm{TSCl}, 2060$ were male (78.6\%) and 561 were female (21.4\%), the male-to-female ratio is close to 3.67:1. The patients' ages ranged from 6 to 92 years, with an average age of $48( \pm 14.9)$ years and a median age of 49 [interquartile range (IQR:38)] years. Among them, $48.0 \pm 14.9$ years for men and $49.4 \pm 14.9$ years for women. According to the age distribution, it was found that young adults aged 21 to 40 make up half of the TSCI population (49.9\%). Regarding the occupation, farmers and herdsmen from rural or pastoral areas account for more than half of the total patients (58.1\%), and the patients from urban areas are mainly workers (11.8\%), students (5.5\%) and retirees (5.6\%). The other occupational groups included government-officer (1.0\%), technician (1.1\%), Enterprisemanagers $(1.1 \%)$, Serviceman $(0.2 \%)$ and others consisting of freelancers, unemployed individuals and self-employed individuals who together accounted for $6.9 \%$ of the total patients. In addition, $8.7 \%$ of patients were unwilling to inform their occupational information or for other reasons. Significantly, from 2017 to 2019 , there were more patients each year than the previous year, while in 2020 there was a decrease of $12.9 \%$ compared with the number of patients in 2019 (figure. 2). 
Table 1

Demographic and etiologic characteristics of patients with TSCI from 2017-2020

\begin{tabular}{|c|c|c|c|c|c|}
\hline \multirow[t]{2}{*}{ Characters } & \multicolumn{5}{|l|}{ Years } \\
\hline & 2017 & 2018 & 2019 & 2020 & Total \\
\hline Total & $546(20.8 \%)$ & $694(26.5 \%)$ & 738(28.1\%) & $643(24.5 \%)$ & $2621(100 \%)$ \\
\hline \multicolumn{6}{|l|}{ Age (Years) } \\
\hline$\leq 20$ & 18(3.3\%) & $21(3.0 \%)$ & $34(4.6 \%)$ & $40(6.2 \%)$ & $113(4.3 \%)$ \\
\hline $21-40$ & $273(50.0 \%)$ & $322(46.4 \%)$ & $432(58.5 \%)$ & $282(43.8 \%)$ & $1309(49.9 \%)$ \\
\hline $41-60$ & 105(19.2\%) & $185(26.7 \%)$ & $140(19.0 \%)$ & 117(18.3\%) & $547(20.9 \%)$ \\
\hline$\geq 61$ & $150(27.5 \%)$ & $166(23.9 \%)$ & 132(17.9\%) & $204(31.7 \%)$ & $652(24.9 \%)$ \\
\hline \multicolumn{6}{|l|}{ Gender } \\
\hline Male & $460(84.2 \%)$ & $538(77.5 \%)$ & $585(79.3 \%)$ & $477(74.2 \%)$ & $2060(78.6 \%)$ \\
\hline Female & $86(15.8 \%)$ & $156(22.5 \%)$ & $153(20.7 \%)$ & $166(25.8 \%)$ & $561(21.4 \%)$ \\
\hline \multicolumn{6}{|l|}{ Occupation } \\
\hline Government-officer & $17(3.1 \%)$ & $4(0.6 \%)$ & $0(0.0 \%)$ & $5(0.8 \%)$ & $26(1.0 \%)$ \\
\hline Technician & $1(0.2 \%)$ & $9(1.3 \%)$ & $18(2.4 \%)$ & $0(0.0 \%)$ & $28(1.1 \%)$ \\
\hline Enterprise-manager & $3(0.5 \%)$ & $1(0.1 \%)$ & $9(1.2 \%)$ & $15(2.3 \%)$ & $28(1.1 \%)$ \\
\hline White-collar worker & $22(4.0 \%)$ & $4(0.6 \%)$ & $1(0.1 \%)$ & $1(0.2 \%)$ & $28(1.1 \%)$ \\
\hline Blue-collar worker & $51(9.3 \%)$ & $73(10.5 \%)$ & $98(13.3 \%)$ & $59(9.2 \%)$ & $281(10.7 \%)$ \\
\hline Farmer and Nomad & $310(56.8 \%)$ & $421(60.7 \%)$ & $413(56.0 \%)$ & $378(58.8 \%)$ & $1522(58.1 \%)$ \\
\hline Student & $42(7.7 \%)$ & $17(2.4 \%)$ & $30(4.1 \%)$ & $54(8.4 \%)$ & $143(5.5 \%)$ \\
\hline Serviceman & $2(0.4 \%)$ & $0(0.0 \%)$ & $4(0.5 \%)$ & $0(0.0 \%)$ & $6(0.2 \%)$ \\
\hline Freelancer & $0(0.0 \%)$ & $16(2.3 \%)$ & $11(1.5 \%)$ & $0(0.0 \%)$ & $27(1.0 \%)$ \\
\hline Self-employed & $10(1.8 \%)$ & $3(0.4 \%)$ & $34(4.6 \%)$ & $46(7.2 \%)$ & $93(3.5 \%)$ \\
\hline Unemployed & $0(0.0 \%)$ & $6(0.9 \%)$ & $21(2.8 \%)$ & $37(5.8 \%)$ & $64(2.4 \%)$ \\
\hline Retired & $43(7.9 \%)$ & $32(4.6 \%)$ & $31(4.2 \%)$ & $40(6.2 \%)$ & 146(5.6\%) \\
\hline Others & $45(8.2 \%)$ & 108(15.6\%) & $68(9.2 \%)$ & $8(1.2 \%)$ & 209(8.7\%) \\
\hline
\end{tabular}

TSCl: Traumatic Spinal Cord Injuries.

Other* included patients who do not want to disclose information or whose information is not clearly documented 


\begin{tabular}{|llllll|}
\hline Characters & \multicolumn{2}{l}{ Years } & & & \\
\cline { 2 - 5 } & 2017 & 2018 & 2019 & 2020 & Total \\
\hline Etiology & & & & \\
\hline Traffic accidents & $120(22.0 \%)$ & $158(22.8 \%)$ & $237(32.1 \%)$ & $111(17.3 \%)$ & $626(23.9 \%)$ \\
\hline Sports and leisure & $28(5.1 \%)$ & $7(1.0 \%)$ & $31(4.2 \%)$ & $3(0.5 \%)$ & $69(2.6 \%)$ \\
\hline Slip fall and low fall & $159(29.1 \%)$ & $185(26.7 \%)$ & $161(21.8 \%)$ & $222(34.5 \%)$ & $727(27.7 \%)$ \\
\hline High fall & $223(40.8 \%)$ & $289(41.6 \%)$ & $228(30.9 \%)$ & $276(42.9 \%)$ & $1016(38.8 \%)$ \\
\hline Other Violence & $16(2.9 \%)$ & $55(7.9 \%)$ & $81(11.0 \%)$ & $31(4.8 \%)$ & $183(7.0 \%)$ \\
\hline TSCl: Traumatic Spinal Cord Injuries. & & & & \\
\hline $\begin{array}{l}\text { Other* included patients who do not want to disclose information or whose information is not clearly } \\
\text { documented }\end{array}$ & & & & \\
\hline
\end{tabular}

\section{Etiology of the patients with TSCI}

Analysis of the acquired etiological data showed that High fall was the leading cause of TSCl, indicating $38.8 \%$ of total patients $(P<0.05)$. followed by slip fall \& low fall $(27.7 \%)$, traffic accidents $(23.9 \%)$, sports (2.6\%). Other violences include falling objects, violent fights and other collisions, they account for $7.0 \%$. Table 2 shows the etiological composition ratio of TSCl in different age groups, in which there is no significant difference in etiological composition ratio between $\leq 20$ years old, 21-40 years old and 61-40 years old groups $(P>0.05)$. However, the proportion of low energy injury factors (i.e. Slip fall or Low fall) was significantly higher in patients $\geq 61$ years old than in other age groups $(P<0.01)$, nearly half $(45.9 \%)$ of patients with TSCl over 60 years old are caused by this factor. Table 3 describes the etiological composition of patients of genders. High fall (43.6\%) is the most common cause of male patients with $\mathrm{TSCl}$, while slip fall / low fall (37.6\%) is the most common cause female patients with TSCl. 
Table 2

The etiological composition ratio of TSCl in different age groups

\begin{tabular}{|c|c|c|c|c|c|c|}
\hline \multirow{2}{*}{$\begin{array}{l}\text { Age } \\
\text { group }\end{array}$} & \multicolumn{6}{|l|}{ Etiology } \\
\hline & $\begin{array}{l}\text { Traffic } \\
\text { accidents }\end{array}$ & Sports & $\begin{array}{l}\text { Slip fall / Low } \\
\text { fall }\end{array}$ & $\begin{array}{l}\text { High } \\
\text { fall }\end{array}$ & $\begin{array}{l}\text { Other } \\
\text { Violence }\end{array}$ & Total \\
\hline \multirow[t]{2}{*}{$\leq 20$} & 30 & 16 & 33 & 27 & 7 & 113 \\
\hline & $(26.5 \%)$ & $(14.2 \%)$ & $(29.2 \%)$ & $(23.9 \%)$ & $(6.2 \%)$ & $(100 \%)$ \\
\hline \multirow[t]{2}{*}{$21-40$} & 326 & 24 & 239 & 592 & 128 & 1309 \\
\hline & $(24.9 \%)$ & $(1.8 \%)$ & (18.3\%) & $(45.2 \%)$ & $(9.8 \%)$ & (100\%) \\
\hline \multirow[t]{2}{*}{$41-60$} & 138 & 15 & 156 & 203 & 35 & 547 \\
\hline & $(25.2 \%)$ & $(2.7 \%)$ & (28.5\%) & $(37.1 \%)$ & $(6.4 \%)$ & (100\%) \\
\hline \multirow[t]{2}{*}{$\geq 61$} & 132 & 14 & 299 & 194 & 13 & 652 \\
\hline & $(20.2 \%)$ & $(2.1 \%)$ & (45.9\%) & $(29.8 \%)$ & $(2.0 \%)$ & (100\%) \\
\hline \multirow[t]{2}{*}{ Total } & 626 & 69 & 727 & 1016 & 183 & 2621 \\
\hline & $(23.9 \%)$ & $(2.6 \%)$ & $(27.7 \%)$ & $(38.8 \%)$ & $(7.0 \%)$ & $(100 \%)$ \\
\hline
\end{tabular}

Table 3

The etiological composition ratio of TSCl in male and female

\begin{tabular}{|c|c|c|c|c|c|c|}
\hline \multirow[t]{2}{*}{ Gender } & \multicolumn{6}{|l|}{ Etiology } \\
\hline & \multirow{2}{*}{ 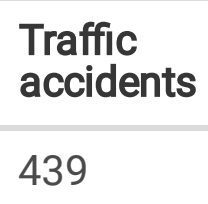 } & Sports & \multicolumn{2}{|c|}{$\begin{array}{l}\text { Slip fall / Low } \\
\text { fall }\end{array}$} & \multirow[t]{2}{*}{ High fall } & $\begin{array}{l}\text { Other } \\
\text { Violence }\end{array}$ \\
\hline Male & & 53 & 516 & 898 & & 2060 \\
\hline & $(21.3 \%)$ & $(2.6 \%)$ & $(25.0 \%)$ & $(43.6 \%)$ & $(7.5 \%)$ & $(100 \%)$ \\
\hline \multirow[t]{2}{*}{ Female } & 187 & 16 & 211 & 118 & 29 & 561 \\
\hline & (33.3\%) & $(2.9 \%)$ & $(37.6 \%)$ & $(21.0 \%)$ & $(5.2 \%)$ & $(100 \%)$ \\
\hline \multirow[t]{2}{*}{ Total } & 626 & 69 & 727 & 1016 & 183 & 2621 \\
\hline & $(23.9 \%)$ & $(2.6 \%)$ & $(27.7 \%)$ & $(38.8 \%)$ & $(7.0 \%)$ & $(100 \%)$ \\
\hline
\end{tabular}

\section{Injury Level}

As can be seen from the statistics in Figure $3, \mathrm{TSCl}$ occurred at the cervical, thoracic, lumbosacral levels, and the proportions in these levels were $33.0 \%, 36.8 \%$ and $30.2 \%$, respectively. Count the number of cases per injury vertebral segment, there were 79.0 patients with single-level spinal fractures and $20.1 \%$ patients with multi-level ( $\geq 2$ levels) spinal fractures. Figure 3 showed that the distribution of segmental injury cases showed a "bimodal" pattern, analysis of this data indicates that the two peak injury levels of TSCI 
were $\mathrm{C} 6$ and $\mathrm{Tl} 1$ vertebra, Overall, L1, T12 and C6 were the most frequently injured segments, accounting for $14.7 \%, 12.2 \%$ and $8.2 \%$ of the total cases, respectively. Further, the injury types of each vertebral segment are divided into fracture-dislocation, distractive flexion fracture (Chance fracture), burst fracture and compression fracture. Roughly analysis, the majority fracture type of TSCI patients due to cervical injury is fracture-dislocation, which type accounts for $59.1 \%$ of cervical injuries; Compression fractures are more common in TSCl patients due to thoracic injury (exclude T12), which type accounts for $48.3 \%$ of thoracic injuries (exclude T12); the majority fracture type of TSCI patients due to lumbosacral injury (include T12) is burst fracture, which type accounts for $55.9 \%$ of thoracic injuries (include T12).

\section{Severity of TSCI}

The severity of patients with TSCI were divided into complete quadriplegia (CQ), incomplete quadriplegia (IQ), complete paraplegia (CP) and incomplete paraplegia (IP) according to the degree of injury as shown in figure 4a., The patients presenting with IQ accounted for most of all patients with TSCl, accounting for $39.53 \%$. The next is IP, accounting for $33.27 \%$. Patients suffered frome complete injury included CQ and $\mathrm{CP}$, they accounted for $21.10 \%$ and $6.10 \%$, respectively. Admission assessment results using the ASIA scale system is shown in figure 4b. From the pie chart of patients with TSCl patients, $26.82 \%$ suffered from complete motor and sensory dysfunction (ASIA A), 11.22\% patients detected as complete motor dysfunction and some part of the sensory function is retained (ASIA B), 24.23\% patients have inefficient motor functions (myodynamia of most of key muscles $<3$, ASIA C) and $37.73 \%$ patients remain useful motor functions (myodynamia of key muscles $>3$, ASIA D).

\section{The period between injury and admission}

We recorded the patient's waiting time from injury to admission. According to the data characteristics, we counted the 975 patients from urban and 1646 patients from rural areas with TSCl separately in figure 5 . It was observed that most urban residents (88\% of 1646 patients) were able to rush to hospital for medical treatment within 1 hour of injury. When most patients $(55.4 \%$ of 1646$)$ with TSCl from rural areas arrived at regional hospitals which is qualified for treatment, $4-7 \mathrm{~h}$ had passed since the time of injury.

\section{The annual count of TSCI patients form urban and rural}

We divided the annual patient count into two groups: those from urban and those from rural areas. From 2017 to 2020 , the annual number of urban patients was 185, 288, 323 and 172, which showed an increasing trend in the first three years, and decreased significantly in 2020 compared with 2019.From 2017 to 2020 , the number of rural patients was $361,406,415$ and 471 , and the number of cases had been rising for four consecutive years. 


\section{Treatment of TSCI and status on discharge}

In terms of the treatment that TSCl patients received, 2002 cases received operative treatment, 619 cases received conservative treatment. We regard the outcomes of the patients treated with operative treatment or conservative treatment as a whole. We can figure out the change in patients' condition after receiving one of the treatments from Table 4. Regardless of the treatment, about three-quarters of patients had no change in their ASIA scales before and after treatment, among them, in the patients who received surgical treatment accounted for $71.6 \%$, in the patients who received conservative treatment accounted for $80 \%$. If ASIA scale was improved than on admission but still at incomplete level (B/C/D), it would be regarded as improvement, with an improvement rate of $22.4 \%$ for those treated surgically, and the improvement rate for those treated conservatively was only $11.6 \%$, about half of the former. Patients with ASIA scale of Grade $E$ at discharge were considered cured, the cure rate of both methods was unsatisfactory, with $4.8 \%$ for operative treatment and $7.1 \%$ for conservative treatment. In addition, there are a few cases of deterioration or death.

Table 4

Treatment of TSCl and functional changes in discharge and admission

\begin{tabular}{|c|c|c|c|c|c|c|}
\hline \multirow{2}{*}{$\begin{array}{l}\text { Treatment of } \\
\text { TSCl }\end{array}$} & \multicolumn{6}{|c|}{ Status on discharge } \\
\hline & Cure $^{\star 1}$ & Improvement*2 & Unchanged*3 & Deterioration ${ }^{4}$ & Death & Total \\
\hline \multirow{2}{*}{$\begin{array}{l}\text { Operative } \\
\text { Treatment }\end{array}$} & 97 & 448 & 1433 & 11 & 13 & 2002 \\
\hline & $(4.8 \%)$ & $(22.4 \%)$ & $(71.6 \%)$ & $(0.5 \%)$ & $(0.6 \%)$ & $(100.0 \%)$ \\
\hline \multirow{2}{*}{$\begin{array}{l}\text { Conservative } \\
\text { Treatment }\end{array}$} & 44 & 72 & 499 & 0 & 4 & 619 \\
\hline & $(7.1 \%)$ & $(11.6 \%)$ & $(80.6 \%)$ & $(0.0 \%)$ & $(0.6 \%)$ & $(100.0 \%)$ \\
\hline \multirow[t]{2}{*}{ Total } & 141 & 520 & 1932 & 11 & 17 & 2621 \\
\hline & $(5.4 \%)$ & $(19.8 \%)$ & $(73.7 \%)$ & $(0.4 \%)$ & $(0.6 \%)$ & $(100.0 \%)$ \\
\hline \multicolumn{7}{|c|}{${ }^{* 1}$ At discharge, ASIA scale reached E; } \\
\hline \multicolumn{7}{|c|}{$\star^{2}$ ASIA scale was improved than on admission but still at incomplete level $(B / C / D)$; } \\
\hline \multicolumn{7}{|c|}{${ }^{\star 3}$ ASIA scale on admission and discharge were the same; } \\
\hline \multicolumn{7}{|c|}{${ }^{* 4}$ ASIA scale was worse than on admission } \\
\hline
\end{tabular}

\section{Estimation of TSCI incidence in Northwest China}

We can only infer the whole from the approximate relationship between the number of beds in our sampling hospital and the regional population covered by them. By referring to the China Statistical Yearbook (https://www.yearbookchina.com/) from 2017 to 2020, we combined the bed data of the five 
provinces in Northwest China and concluded that the average annual bed in Northwest China during the four years was 6.194 beds per thousand people. The total number of beds in the 14 sampled hospitals was about 30,000 , so it is estimated that the hospitals could cover a population of $30,000 / 6.194 \times 10^{-3}=4,843,397$. The four-year incidence rate of TSCl can be estimated as the ratio of TSCI patients number admitted by the hospital to the total population covered by the hospital. These hospitals treated 2,621 patients with TSCI in the four years from 2017 to 2020. If we use these samples to estimate the population, the four-year incidence rate of TSCI (per million people) was calculated to be 541.15 cases in the population covered by these hospitals. According to the survey data (Figure 2), the annual incidence rates from 2017 to 2020 are 112.4, 143.4,152.2 and 132.6 per million people respectively.

\section{Discussion}

Northwest China is an economically backward region in China with low coverage of health insurance and educational level, but it is still developing rapidly. A large number of people are engaged in traditional manual labor or industrial production. Traffic factors and falls are both important injury factors for TSCl in labor force (industry, agriculture and husbandry). In the past, we have conducted single-center studies [15] However, despite its under-development with low population density, the total area of five provinces in northwest China is nearly 3.08 million square kilometers, which is a vast area covers about $1 / 3$ land area of China. In order to get timely treatment, local patients usually choose a nearby medical center. Therefore, multi-center study in multiple regions can better represent the whole region than single-center research. We collected the data of patients with TSCl admitted to 14 hospitals located in QH, SN-N, SN-C, SN-S to understand the changes in the incidence of spinal cord injury patients before and after the emergence of COVID-19 (2017-2020). It can optimize the allocation of medical resources then provide timely healthcare to the population of more areas.

Annual count result demonstrated an increasing trend in TSCl patient count from 2017 to 2019, This trend is consistent with previous research findings. $[6,15,16]$ Unusually, the patient count in 2020 was significantly lower than the previous year, there were $12.8 \%$ fewer patients in 2020 than in 2019 . We speculate that this is due to the shutdown and some "work-at-home" proposals implemented by the Chinese government in the first two quarters of 2020 to prevent the COVID-19 epidemic. Recent studies of other traumatic diseases have reached similar conclusions.[17-19] In addition, from the perspective of patients from urban or rural areas, the impact of these policies on urban population is far greater than that of rural population, the number of patients in urban population in 2020 is only $53.3 \%$ of the last year, while the number of patients in rural areas in 2020 is still increasing compared with the previous year. We consider this to be related to the feasibility of shutdown policies and "work-at-home" proposals. In cities, where there are more office workers and students, it is easier to work or study online, which largely shields them from the exposure of many outdoor injury factors, while agricultural or livestock production is hard to move online. Another indication is that the proportion of patients aged over 60 in 2020 shows a significant increase. Due to bone degenerative changes and hypofunction of sensory and motor, nontraffic and low-energy injury factors are more likely to cause TSCl in elderly people Compared with young 
and middle-aged people. [20,21] Combined with the epidemic policy mentioned earlier, this evidence is consistent with our conclusions. Although the COVID-19 pandamic brings immeasurable economic losses and damages human health, it also facilitates the development of online work and learning, which makes it possible for many jobs to be performed online at home for a long time. From our conclusion, promoting online office work and learning will make a lot of sense to reduce the incidence of traumatic diseases among people at labor age, especially for urban resident.

In our investigation, the male to female ratio in patients with TSCI was 3.67:1, it is similar to the rate reported in other regions. $[6,14,22]$ This indicates that most of the patients with $\mathrm{TSCl}$ are male. This can be attributed to the fact that most workers in dangerous, physically demanding jobs are male, and that a greater proportion of drivers are male, too.

Most of the injuries were in the $21-40$ age group $(49.9 \%, 1309$ cases), followed by the $\geq 61$ age group $(24.9 \%, 652$ cases) and $41-60$ age group $(20.9 \%, 547$ cases). There are two age groups with high incidence. Such a "bimodal" trend seems to be different from the conclusions of previous studies. Most of the previous literatures described a "unimodal" trend with the highest age group around $40 \pm 10$ years old. $[6,23,24]$ This may be due to the difference in group spacing and the increased incidence of the elderly under the 2020 epidemic policy. The mean age of patients in our data was $48( \pm 14.9)$, which was higher than the domestic average age and global average age given by previous literatures. $[10,25]$ We estimate that this result may be influenced by the aging of society and the policy of delaying retirement time.

Our study also revealed the etiology of the patients with TSCI in Northwest China, included high falls (41.0\%), traffic (23.9\%), sports (2.6\%), low fall (27.7\%), high fall (38.8\%) and other violence (7.0\%). Groups were observed according to age firstly, we find that high energy injury factors, such as high fall, were the most common cause of $\mathrm{TSCl}$ in $21-40$ and $41-60$ age groups, accounting for $45.2 \%$ and $37.1 \%$, respectively and for people over 60 years old, low energy factors, such as low falls or slips, accounted for $45.9 \%$ of the total cases. This is consistent with the conclusion of the study in Guangdong province. [6] Then groups were observed according to gender, result indicated that male group was more likely to have high energy factors causing TSCl.

Integrate the above etiological results, the age of high incidence of TSCI is still dominated by the labor age, especially male. So the labor security agencies of governments and the employers of workers should also strengthen labor safety measures and enhance safety education for employees. [13] In addition, the specialization and mechanization of agricultural and animal husbandry workers should be promoted so that dangerous and strenuous manual labour can be left to machines as far as possible.

Spinal cord injury is usually associated with spinal cord injury, and the levels of injury are corresponding. We counted the segments of the patient's vertebra and the types of fractures, it is the same as the previous literature, the proportions of injuries in cervical, thoracic and lumbar vertebra were similar, and the high incidence of spinal fracture caused by TSCI in each part was C5-C6, T11-T12, and L1-L2. The distribution of injury segments showed a "bimodal" distribution with C6 and L1 as the centers, with 1-2 
adjacent segments. $[23,26]$ On the whole, the T11-L3 segment had the highest proportion of injuries, with a total of 1397 cases, accounting for $42.6 \%$ of all injured cases. The main fractural types of cervical, thoracic and lumbar vertebrae are also different, which is related to their anatomical structure and mechanical characteristics.

From the severity of the injury and the outcome of treatment, our results reveal a less optimistic condition after treatment. As a result of consensus, incomplete injury (72.8\%) occurred more often than complete injury (27.2\%). Given the large number of patients with incomplete TSCl, this issue should be the focus of basic research related to neural regeneration, such as "how to promote the compensation of surviving neurons in the injured area" or "how to achieve differentiation of uninjured stem cells into neurons in the incomplete injured segment". [27] ASIA scale of most patients did not change before and after treatment both in operational group $(71.6 \%)$ or conservative group (80.6\%). This illustrates the importance of prevention in improving tertiary prevention measures and rehabilitation techniques as an important guarantee of improved treatment outcomes. Moreover, the patients who were treated operationally had a higher improvement rate $(22.4 \%)$ and deterioration rate $(0.5 \%)$ than the patients who were treated conservatively (improvement rate is $11.6 \%$, deterioration rate is $0.0 \%$ ). Therefore, improving surgical methods on the basis of reducing postoperative complications is also a strategy to improve the efficacy of TSCl.

Our study also focused on urban-rural differences that had not previously been noticed by investigators. The annual difference in the number of cases was mentioned earlier, and we also compared the length of time between the onset and the treatment of patients in urban and rural areas. From our results, we can see that almost all urban residents can rush to the hospital for emergency treatment after get injured immediately $(<1 \mathrm{~h})$, whereas by the time most patients from rural areas arrive at the hospital for treatment, it has been 4 to 7 hours since they were injured. This reflects the delay in the treatment of patients caused by poor transport conditions in rural areas. In fact, some hospitals in developed areas are already using helicopter emergency medical service (HEMS) to save treatment time for patients in remote areas. [28] This kind of traffic measure is not restricted by the topography and is of great significance for patients with various acute diseases in rural areas such as the Loess Plateau and the Qinghai-Tibet Plateau in Northwest China. The problem is the high cost of HEMS, which also requires better allocation of resources and funding by the public health system.

Finally, we estimated the incidence of TSCI in Northwest China based on the hospital coverage population from 2017 - 2020, the incidence ranged from 112.2 to 152.4 cases per million people. That is higher than 23.7 per million people in Tianjin and 60.6 per million people in Beijing. [29, 30] The incidence of TSCl is difficult to calculate due to the unpredictability of the occurrence of trauma. Sampling methods, inclusion criteria, regional demographic differences and other factors will affect the results. Our estimated results only provide a reference for the incidence of TSCl in northwest China, and more scientific design and observational studies are needed to accurately obtain its incidence. 
However, as a retrospective study, there are irreparable misrecords or incomplete information in the data we obtained, which may lead to deviation between our results and the actual situation. Furthermore, we ignore the data of treatment cost and medicare coverage, which can well reflect the economic pressure of patients and the development level of the region. Therefore, there is insufficient evidence in some descriptions of the severity of TSCl in Northwest China.

\section{Conclusions}

In general, we used multicenter sampling, which made our data more reflective of the overall situation in Northwest China, and we discussed the impact of COVID-19 disease control policies and rural-urban differences on $\mathrm{TSCl}$ incidence. In addition to the conclusions similar to other studies, we also have some findings worth exploring. Due to the implementation of COVID-19 prevention and control measures, the incidence of TSCl among urban residents has decreased to a certain extent. Therefore, we suggest that the promotion of online office and learning is the effective primary prevention measures for traumatic diseases. Besides, due to the differences between urban and rural areas, rural patients need to spend more time to get to the good conditional hospital for treatment, and the problem of emergency transfer service still needs to be addressed.

\section{Abrasives}

TSCl: Traumatic spinal cord injuries; COVID-19: Corona Virus Disease 2019; ASIA scale: American Spinal Injury Association impairment scale; ICD-10: International Classification of Diseases, Version 10; China CDC: China Center for Disease Control; HEMS: helicopter emergency medical service.

\section{Declarations}

Acknowledgement: We thank hospitals for their assistance in collecting information of patients.

Conflict of interests: The authors declare no competing interests.

Funding: This study was supported by the Key Program from the China National Natural Science Funds (81830077); the General Program from the China National Natural Science Funds (81772357);

Ethics approval and informed consent: This study was granted ethical approval from the Ethics Committee of Honghui Hospital, Xi'an Jiaotong University. The Ethics Committee of Honghui Hospital, Xi'an Jiaotong University approved the review process and waived the requirement to obtain patients' written informed consent.

Authors' contributions: XHW, JPD contributed to the study design. All authors contributed to the information collection. XHW, JPD, and CJ contributed to the data processing and analysis; DJH providing financial support and overall guidance. 
Availability of data and materials: All data generated or analyzed during this study are included in Pictures and tables of this article.

\section{References}

1. Kumar R, Lim J, Mekary RA, Rattani A, Dewan MC, Sharif SY, Osorio-Fonseca E, Park KB. (2018). Traumatic Spinal Injury: Global Epidemiology and Worldwide Volume. WORLD NEUROSURG, 113, E345-E363. doi: 10.1016/j.wneu.2018.02.033

2. Furlan JC, Sakakibara BM, Miller WC, Krassioukov AV. (2013). Global Incidence and Prevalence of Traumatic Spinal Cord Injury. CAN J NEUROL SCI, 40(4), 456-464. doi:

$10.1017 /$ S0317167100014530

3. Jabbour P, Fehlings $M$, Vaccaro AR, Harrop JS. (2008). Traumatic spine injuries in the geriatric population. NEUROSURG FOCUS, 25(5), E16. doi: 10.3171/FOC.2008.25.11.E16

4. Venkatesh K, Ghosh SK, Mullick M, Manivasagam G, Sen D. (2019). Spinal cord injury: pathophysiology, treatment strategies, associated challenges, and future implications. CELL TISSUE RES, 377(2), 125-151. doi: 10.1007/s00441-019-03039-1

5. Ahuja CS, Nori S, Tetreault L, Wilson J, Kwon B, Harrop J, Choi D, Fehlings MG. (2017). Traumatic Spinal Cord Injury-Repair and Regeneration. NEUROSURGERY, 80(3S), S9-S22. doi:

10.1093/neuros/nyw080

6. Yang R, Guo L, Huang L, Wang P, Tang Y, Ye J, Chen K, Hu X, Cai Z, Lu C, Wu Y, Shen H. (2017).

Epidemiological Characteristics of Traumatic Spinal Cord Injury in Guangdong, China. SPINE, 42(9), E555-E561. doi: 10.1097/BRS.0000000000001896

7. Yang Y, Fan Y, Zhang H, Zhang Q, Zhao Y, Xiao Z, Liu W, Chen B, Gao L, Sun Z, Xue X, Shu M, Dai J. (2021). Small molecules combined with collagen hydrogel direct neurogenesis and migration of neural stem cells after spinal cord injury. BIOMATERIALS, 269, 120479. doi:

10.1016/j.biomaterials.2020.120479

8. Beck B, Cameron PA, Braaf S, Nunn A, Fitzgerald MC, Judson RT, Teague WJ, Lennox A, Middleton JW, Harrison JE, Gabbe BJ. (2019). Traumatic spinal cord injury in Victoria, 2007-2016. MED J AUSTRALIA, 210(8), 360-366. doi: 10.5694/mja2.50143

9. Jain NB, Ayers GD, Peterson EN, Harris MB, Morse L, O Connor KC, Garshick E. (2015). Traumatic Spinal Cord Injury in the United States, 1993-2012. JAMA, 313(22), 2236. doi:

10.1001/jama.2015.6250

10. Liu P, Yao Y, Liu M, Fan W, Chao R, Wang Z, Liu Y, Zhou J, Zhao J. (2012). Spinal Trauma in Mainland China From 2001 to 2007. SPINE, 37(15), 1310-1315. doi: 10.1097/BRS.0b013e3182474d8b

11. Chang F, Zhang Q, Sun M, Yu H, Hu L, Wu J, Chen G, Xue L, Lu J. (2017). Epidemiological study of Spinal Cord Injury individuals from halfway houses in Shanghai, China. The Journal of Spinal Cord Medicine, 41(4), 450-458. doi: 10.1080/10790268.2017.1367357 
12. Guo H, Liu J, Qi X, Ning G, Zhang H, Li X, Ma X. (2012). Epidemiological characteristics of adult SCIWORA in Tianjin, China: a preliminary study. EUR SPINE J, 21(1), 165-171. doi: 10.1007/s00586011-2041-x

13. Liu J, Liu H, Gao F, Li J, Li J. (2020). Epidemiological features of traumatic spinal cord injury in Beijing, China. The Journal of Spinal Cord Medicine, 1-7. doi: 10.1080/10790268.2020.1793505

14. Chen R, Liu X, Han S, Dong D, Wang Y, Zhang H, Shi J, Zhao C, Yao M. (2017). Current epidemiological profile and features of traumatic spinal cord injury in Heilongjiang province, Northeast China: implications for monitoring and control. SPINAL CORD, 55(4), 399-404. doi: $10.1038 /$ sc. 2016.92

15. Wang Z, Zou P, Yang J, Liu T, Song L, Lu Y, Guo H, Zhao Y, Liu T, Hao D. (2020). Epidemiological characteristics of spinal cord injury in Northwest China: a single hospital-based study. J ORTHOP SURG RES, 15(1), 214. doi: 10.1186/s13018-020-01729-z

16. Ning G, Mu Z, Shangguan L, Tang Y, Li C, Zhang Z, Zhou Y. (2016). Epidemiological features of traumatic spinal cord injury in Chongqing, China. The journal of spinal cord medicine, 39(4), 455460. doi: 10.1080/10790268.2015.1101982

17. Camine T, Rembisz A, Barron R, Baldwin C, Kromer M. (2020). Decrease in Trauma Admissions with COVID-19 Pandemic. Western Journal of Emergency Medicine, 21(4), 819-822. doi: 10.5811/westjem.2020.5.47780

18. Keays G, Freeman D, Gagnon I. (2020). Injuries in the time of COVID-19. Health Promotion and Chronic Disease Prevention in Canada, 40(11/12), 336-341. doi: 10.24095/hpcdp.40.11/12.02

19. Pinggera D, Klein B, Thomé C, Grassner L. (2021). The influence of the COVID-19 pandemic on traumatic brain injuries in Tyrol: experiences from a state under lockdown. EUR J TRAUMA EMERG S, 47(3), 653-658. doi: 10.1007/s00068-020-01445-7

20. de Melo-Neto JS, de Campos Gomes F, de Morais DF, Tognola WA. (2017). Spinal cord injury in elderly patients admitted to a tertiary hospital. J BACK MUSCULOSKELET, 30(4), 929-936. doi: 10.3233/BMR-169686

21. Bub LD, Blackmore CC, Mann FA, Lomoschitz FM. (2005). Cervical Spine Fractures in Patients 65 Years and Older: A Clinical Prediction Rule for Blunt Trauma. RADIOLOGY, 234(1), 143-149. doi: 10.1148/radiol.2341031692

22. Ackery A, Tator C, Krassioukov A. (2004). A Global Perspective on Spinal Cord Injury Epidemiology. J NEUROTRAUM, 21(10), 1355-1370. doi: 10.1089/neu.2004.21.1355

23. Du J, Hao D, He B, Yan L, Tang Q, Zhang Z, Wang Y, Li H, Cao Y, Jiang C, Bai L. (2021). Epidemiological characteristics of traumatic spinal cord injury in Xi'an, China. SPINAL CORD, 59(7), 804-813. doi: 10.1038/s41393-020-00592-3

24. Yang R, Guo L, Wang P, Huang L, Tang Y, Wang W, Chen K, Ye J, Lu C, Wu Y, Shen H. (2014). Epidemiology of Spinal Cord Injuries and Risk Factors for Complete Injuries in Guangdong, China: A Retrospective Study. PLOS ONE, 9(1), e84733. doi: 10.1371/journal.pone.0084733 
25. Wyndaele M, Wyndaele J. (2006). Incidence, prevalence and epidemiology of spinal cord injury: what learns a worldwide literature survey? SPINAL CORD, 44(9), 523-529. doi: 10.1038/sj.sc.3101893

26. Taşoğlu Ö, Koyuncu E, Daylak R, Karacif DY, İnce Z, Yenigün D, Özgirgin N. (2017). Demographic and clinical characteristics of persons with spinal cord injury in Turkey: One-year experience of a primary referral rehabilitation center. The Journal of Spinal Cord Medicine, 41(2), 157-164. doi: 10.1080/10790268.2016.1224215

27. O Shea TM, Burda JE, Sofroniew MV. (2017). Cell biology of spinal cord injury and repair. J CLIN INVEST, 127(9), 3259-3270. doi: 10.1172/JCI90608

28. Rzońca P, Gałązkowski R, Wójcik-Fatla A, Panasiuk L, Gotlib J. (2019). Missions of the Helicopter Emergency Medical Service in rural and urban areas in Poland - A comparative retrospective analysis. ANN AGR ENV MED, 26(2), 355-360. doi: 10.26444/aaem/106223

29. Ning G, Yu T, Feng S, Zhou X, Ban D, Liu Y, Jiao X. (2011). Epidemiology of traumatic spinal cord injury in Tianjin, China. SPINAL CORD, 49(3), 386-390. doi: 10.1038/sc.2010.130

30. Li J, Liu G, Zheng Y, Hao C, Zhang Y, Wei B, Zhou H, Wang D. (2011). The epidemiological survey of acute traumatic spinal cord injury (ATSCI) of 2002 in Beijing municipality. SPINAL CORD, 49(7), 777782. doi: $10.1038 / \mathrm{sc} .2011 .8$

\section{Figures}



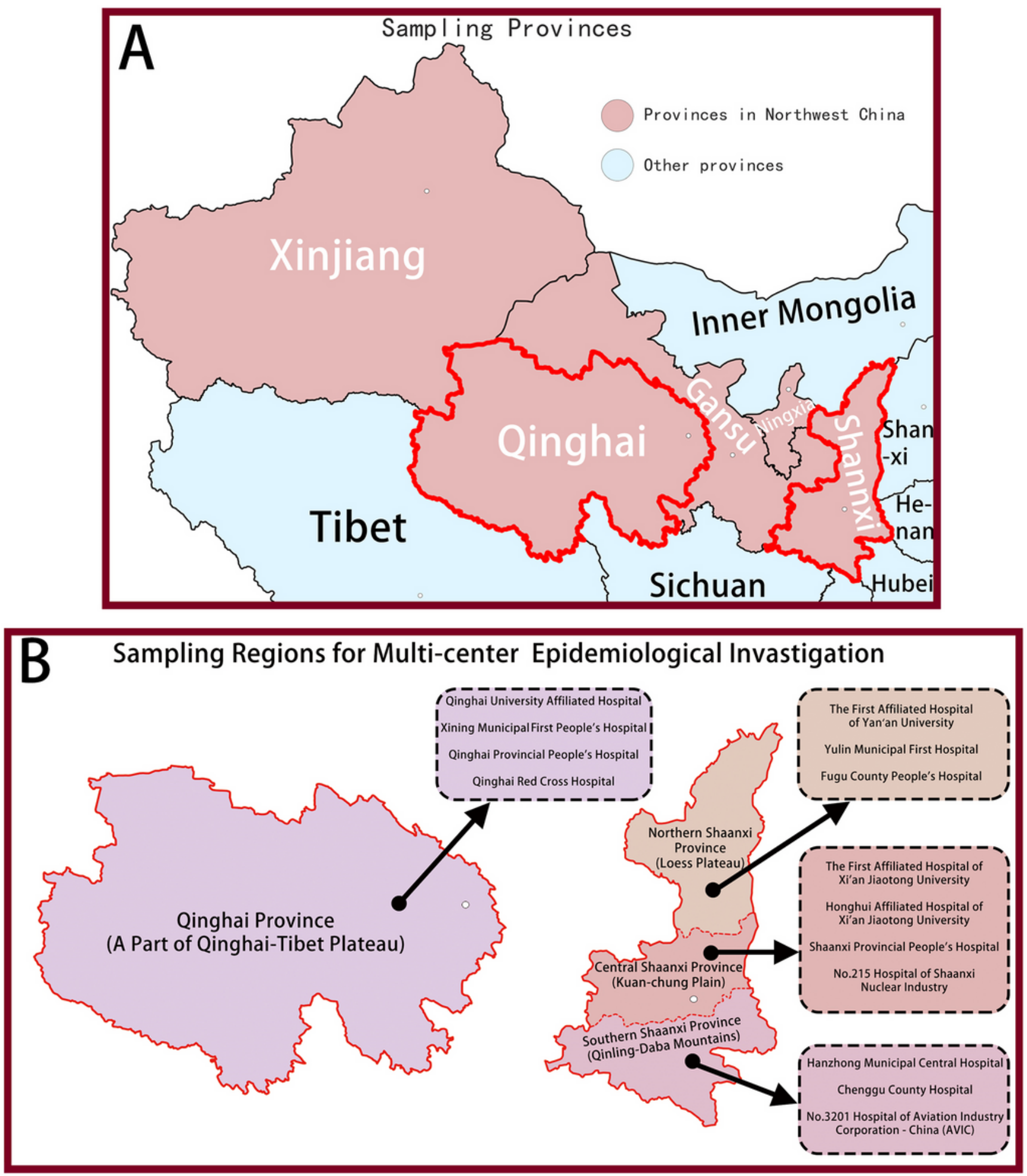

Figure 1

A total of 2621 patients form 14 hospitals in two provinces with TSCl were identified in this study (A) Sampling Provinces; (B) Sampling Regions for Multi-center Epidemiological Investigation. 


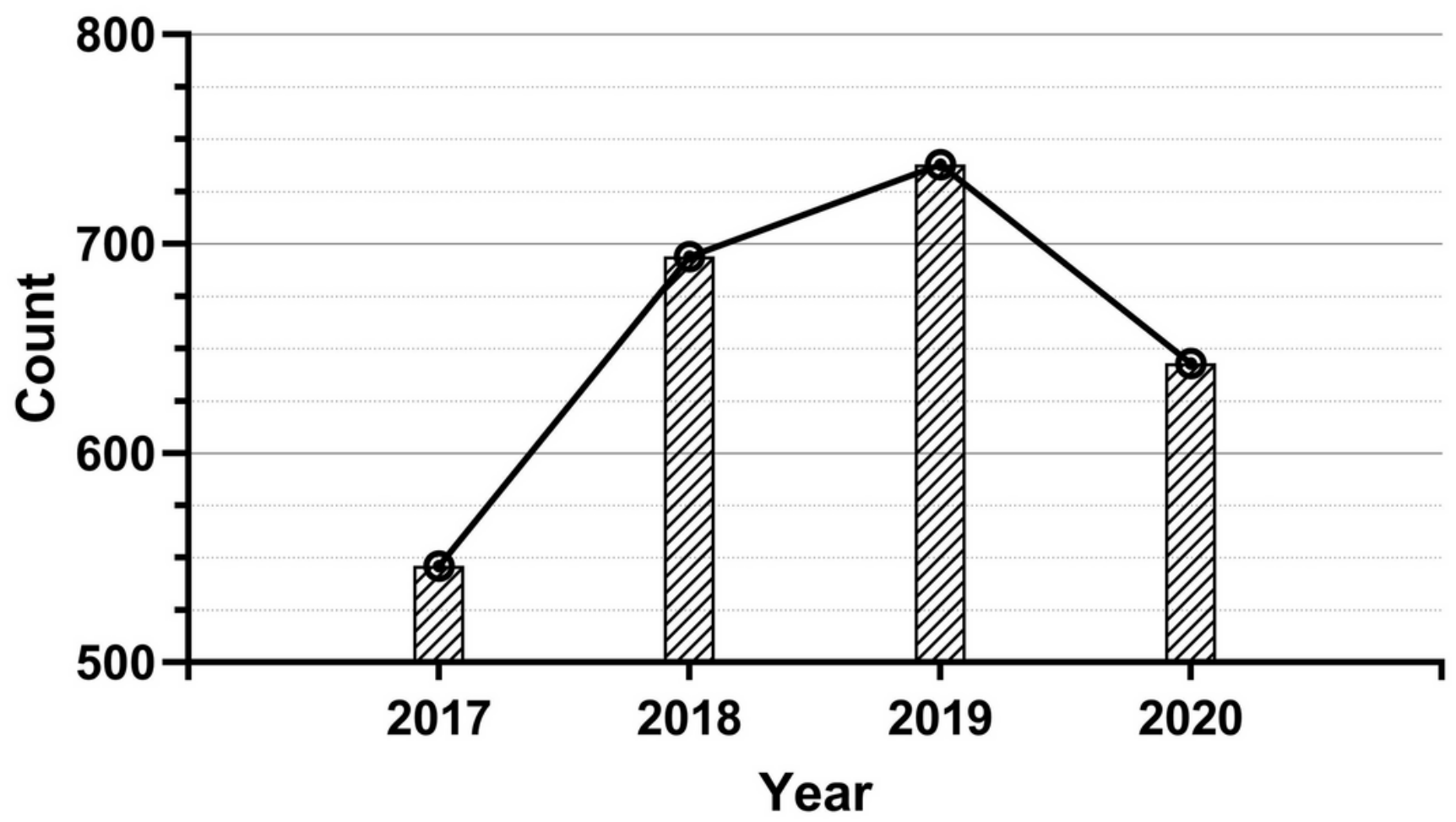

Figure 2

The annual count of TSCI patients during 2017-2020. 


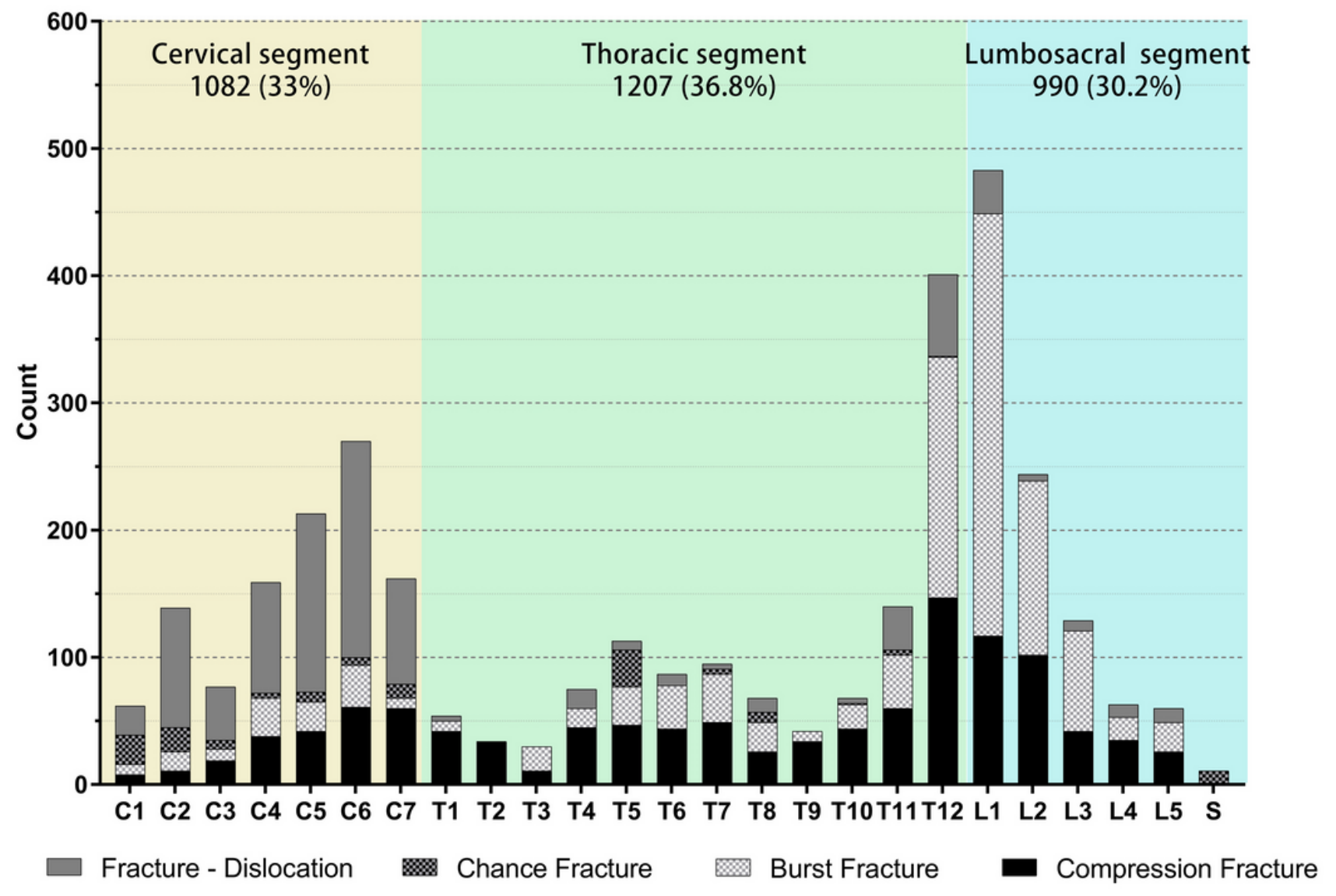

Figure 3

Distribution of fracture level for TSCl patients by the type of fracture. $(n=2621)$ 
A

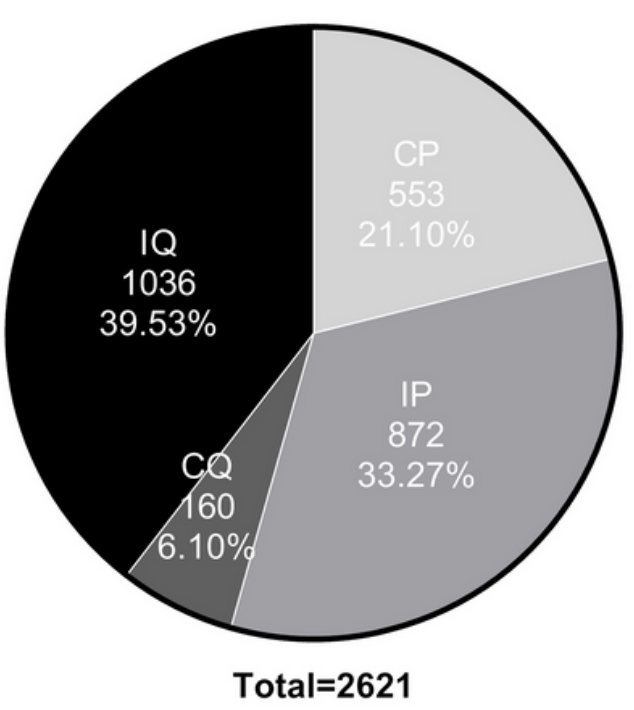

$\mathrm{CQ}=$ complete quadriplegia

$\mathrm{IQ}=$ incomplete quadriplegia

$\mathrm{CP}=$ complete paraplegia

IP = incomplete paraplegia
B

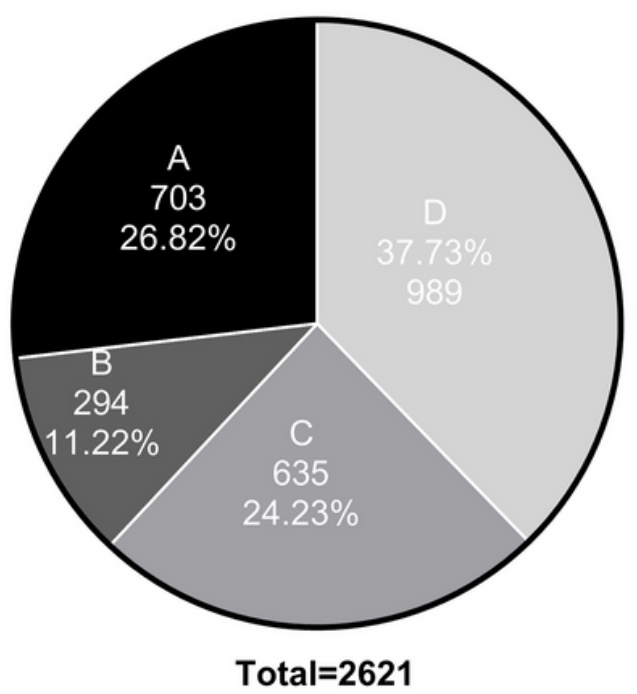

$A=$ Complete: No motor or sensory function is preserved in the sacral segments S4-S5. $\mathrm{B}=$ Incomplete: Sensory but not motor function is preserved below the neurological level and includes the sacral segments \$4-\$5.

$\mathrm{C}=$ Incomplete: Motor function is preserved below the neurological level, and more than half of key muscles below the neurological level have a muscle grade less than 3. $\mathrm{D}=$ Incomplete: Motor function is preserved below the neurological level, and at least half of key muscles below the neurological level have a muscle grade of 3 or more.

$E=$ Normal: motor and sensory functions are normal.

\section{Figure 4}

The severity of patients with TSCl: (A) The degree of injury; (B) Their spinal function after injury evaluated by ASIA impairment scale.

\section{A The period between $\mathrm{TSCl}$ and admission}

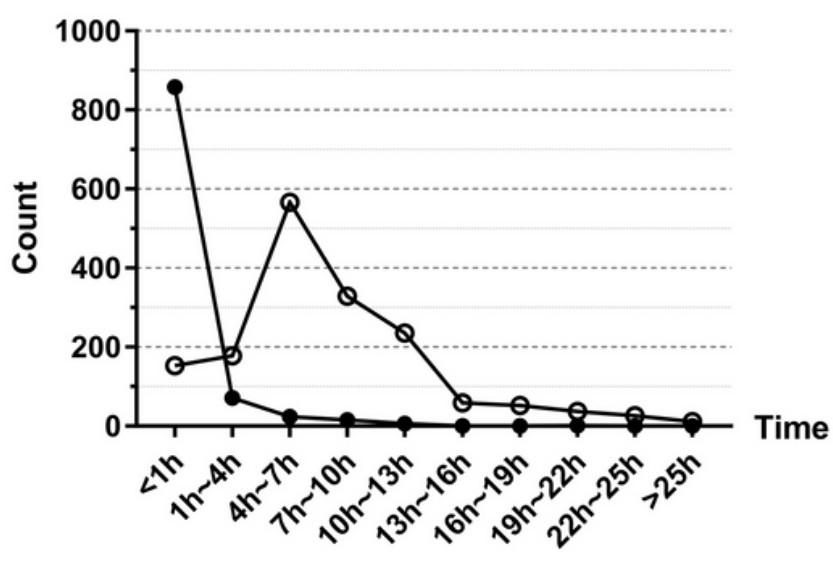

B The annual count of TSCl patients form urban/rural

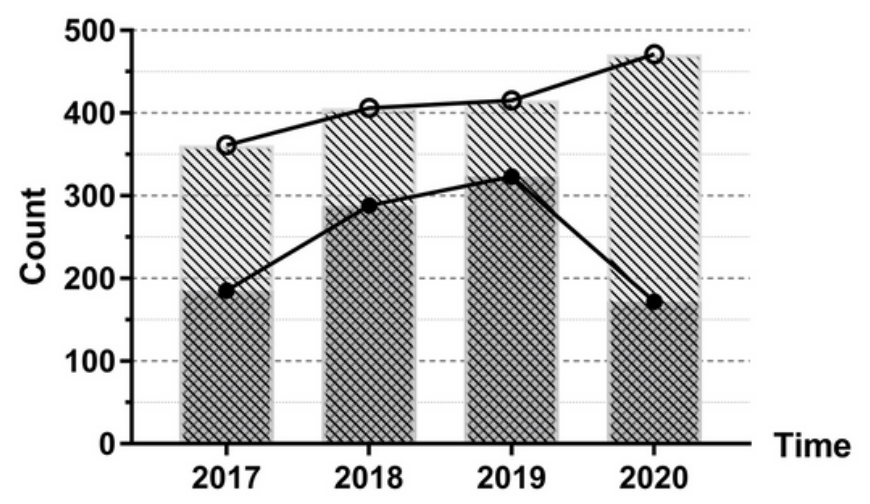

From Urban areas

From Farming/Pastoral Areas

\section{Figure 5}

Urban and rural differences in patient treatment: $(A)$ The patient's waiting time from injury to admission; (B) The annual count of TSCl patients form urban and rural. 